\title{
Professional Characteristics and Concerns of Instructors Teaching English as a Second Language to Adults in Non-Credit Programs in Ontario
}

\section{Razika Sanaoui}

\begin{abstract}
A survey was conducted to describe professional characteristics of instructors teaching English as a Second Language (ESL) to adults in non-credit programs in Ontario. This province-wide survey was the first data-gathering phase in a three-phase project leading to the establishment of a protocol and uniform standards for the certification of instructors teaching non-credit Adult ESL in Ontario. The study was initiated by the Teachers of ESL Association of Ontario (TESL Ontario) and conducted in collaboration with the Ontario Ministry of Education and Training. Findings provided detailed descriptions of professional characteristics of 1,196 respondents, including their age and gender, educational backgrounds and professional qualifications, teaching experience, employment, conditions of employments, and opportunities for professional development. Professional issues of concern to the instructors and their recommendations for addressing these issues were also summarized.
\end{abstract}

\section{Introduction}

\section{Purpose of the Project}

The purpose of this project was to describe professional characteristics of instructors teaching English as a Second Language (ESL) to adults in noncredit programs in Ontario, specifically the instructors' educational backgrounds, professional qualifications, teaching experience, employment, conditions of employment, and access to opportunities for professional development. The research approach taken in the project was to conduct a survey eliciting this information from a large sample of instructors who were currently teaching non-credit Adult ESL in all types of institutions offering non-credit ESL programs for adults in Ontario. This survey was the first data-gathering phase in a three-phase project leading to the establishment of a protocol and uniform standards for the certification of instructors teaching non-credit Adult ESL in Ontario. Findings from this survey are intended to provide the Ontario Ministry of Education and Training (OMET), the Teachers of ESL Association of Ontario (TESL Ontario), Citizenship and Immigration Canada, and the Ontario Ministry of Citizenship, Culture and Recreation with a descriptive profile of the instructors for whom a uniform 
certification protocol and standards will be established in the third phase of the project. The description of these instructors' characteristics and current situation highlights a broad range of concerns that are also relevant to adult ESL education in other parts of Canada.

\section{Context for the Project}

The project has brought together several agencies, namely, the Ontario Ministry of Education and Training, TESL Ontario, Citizenship and Immigration Canada, and the Ontario Ministry of Citizenship, Culture and Recreation to address collaboratively the current lack of a protocol and uniform standards in Ontario for the certification of non-credit Adult ESL instructors. In the first phase of the project, funded by the Ontario Ministry of Education and Training, professional characteristics of 1,196 of these instructors are described, providing detailed information that was not readily available from other sources. The second phase of the project was funded by Citizenship and Immigration Canada and the Ontario Ministry of Citizenship, Culture and Recreation. Its objective was to describe all teacher education programs in Ontario that issue certificates or diplomas in Teaching English as a Second / Foreign Language. These programs offered by public institutions as well as private agencies seemingly varied in their requirements for issuing TESL certificates or diplomas. A province-wide survey aimed to compile a comprehensive list and detailed descriptions of individual programs, including their admission requirements, length of the programs and number of hours of instruction, course contents, length and nature of teaching practica, student enrollment and tuition fees, professional credentials of instructors teaching in the programs, and types of certificates issued on completion of the programs. This second phase of the project was initiated in January 1996. Descriptions of ESL teacher preparation programs were recently compiled in a directory (Sanaoui, 1997).

The compilation of findings from the two surveys (i.e., a detailed profile of instructors teaching non-credit Adult ESL in Ontario and a directory describing programs that prepare and issue credentials to ESL instructors) will inform decision-making in the third phase of the project, the objectives of which are to develop and validate a protocol and uniform standards for the certification of instructors of non-credit Adult ESL in Ontario. In this third phase focus groups will be organized to represent various stakeholders, in and outside the ESL community and will be informed of the results of the two surveys. These focus groups will:

1. examine academic, professional, legal, financial, social, and political issues associated with the development of uniform standards and a protocol for certifying instructors of non-credit Adult ESL;

2. consider ESL certification standards and protocols implemented in other Canadian provinces (especially in British Colombia and Alberta 
where such protocols and standards have been in place for several years), in other countries (for example, Britain, Australia, and the United States), and models for professional certification adopted by other professions in Ontario (e.g., early childhood educators);

3. formulate guiding principles for the creation of a protocol and standards for certification most appropriate to the Ontario context and situation of non-credit Adult ESL instructors. (This stage will involve making decisions on all aspects of the process, including selection of the agency that would be responsible for issuing certification to instructors, procedures and costs for administering the certification protocol, and types of standards to be applied when issuing certification);

4. establish a steering committee responsible for creating a protocol and defining certification standards that conform to the guiding principles generated by the focus groups. This third phase of the project, co-funded by the Ontario Ministry of Education and Training, and Citizenship and Immigration Canada will be carried out from January to December 1997. Pending further funding a pilot study would be conducted subsequently to validate the protocol and standards of certification prior to their implementation.

The links that have been established between the Ontario Ministry of Education, TESL Ontario, Citizenship and Immigration Canada, and the Ontario Ministry of Citizenship, Culture and Recreation for the purposes of planning and conducting this project are noteworthy. As Harrold (1995) pointed out in a review of the ongoing processes toward ESL teacher certification in Canada, professional associations of ESL teachers engaged in developing similar certification protocols and standards in other Canadian provinces have encountered difficulties obtaining approval from governmental agencies when participation of these agencies was not successfully established at the outset.

\section{The Survey}

A province-wide survey was conducted collaboratively by OMET and TESL Ontario during the period February 1, 1995 to March 31, 1996 to describe professional characteristics of instructors teaching non-credit Adult ESL in Ontario. Data collection was conducted by OMET. The survey questionnaire was piloted with instructors teaching non-credit Adult ESL at the Bickford Adult Center of the Toronto Board of Education and subsequently revised according to comments provided by these participants. The questionnaire (appearing in Appendix A) was then distributed to all universities, colleges, school boards, community-based and private agencies in Ontario offering non-credit ESL programs for adults (the list of institutions surveyed by OMET is kept on file at the TESL Ontario office). Administrators of non- 
credit Adult ESL programs in these institutions received 20 copies of the survey questionnaire in March 1995 with instructions from OMET to distribute them to all instructors currently teaching non-credit Adult ESL courses in their individual programs. The program administrators were asked to make additional copies of the questionnaire according to their needs or request additional copies from OMET. Confidentiality was guaranteed to all instructors who participated in the survey; individuals were not asked to indicate their names on the questionnaires, and they were given the option of returning their completed questionnaires (in sealed envelopes) independently of or via their program administrators.

A total of 1,196 completed questionnaires were returned to OMET. TESL Ontario was responsible for conducting analyses on the data obtained, as well as interpreting and reporting the survey findings. The data were coded according to categories developed in consultation with OMET's Statistical Services staff and entered into computer files for the purpose of statistical analyses. Quantitative analyses consisting mostly of calculations of percentages were conducted on the data to describe characteristics of the respondents. Qualitative analyses were conducted on data obtained from the respondents in two open-ended questions (questionnaire items 5 and 6) asking them to report professional issues of concern to them and to suggest ways in which their concerns might be addressed. The instructors' responses were compiled into computer files as verbatim quotations that were subsequently grouped according to general categories describing the types of issues the respondents identified and recommendations they offered. ${ }^{1}$

\section{Findings}

Findings from analyses conducted on 1,196 completed questionnaires are reported in the next two sections. Findings from quantitative analyses are presented first under the headings Demographic Information, Education, Teaching Experience, Employment, Conditions of Employment, and Professional Development. Then professional issues of concern reported by the respondents and recommendations they made for addressing these issues are summarized.

\section{Professional Characteristics of Instructors Teaching Non-Credit Adult ESL \\ Demographic Information}

Figure 1 shows the number of male and female respondents. A total of $87 \%$ of the instructors were women, whereas $13 \%$ were men. The respondents' ages ranged from 23-73 with a mean of 43 . Table 1 shows the number and percentage of instructors in their 20s, 30s, 40s, 50s, and 60s. 


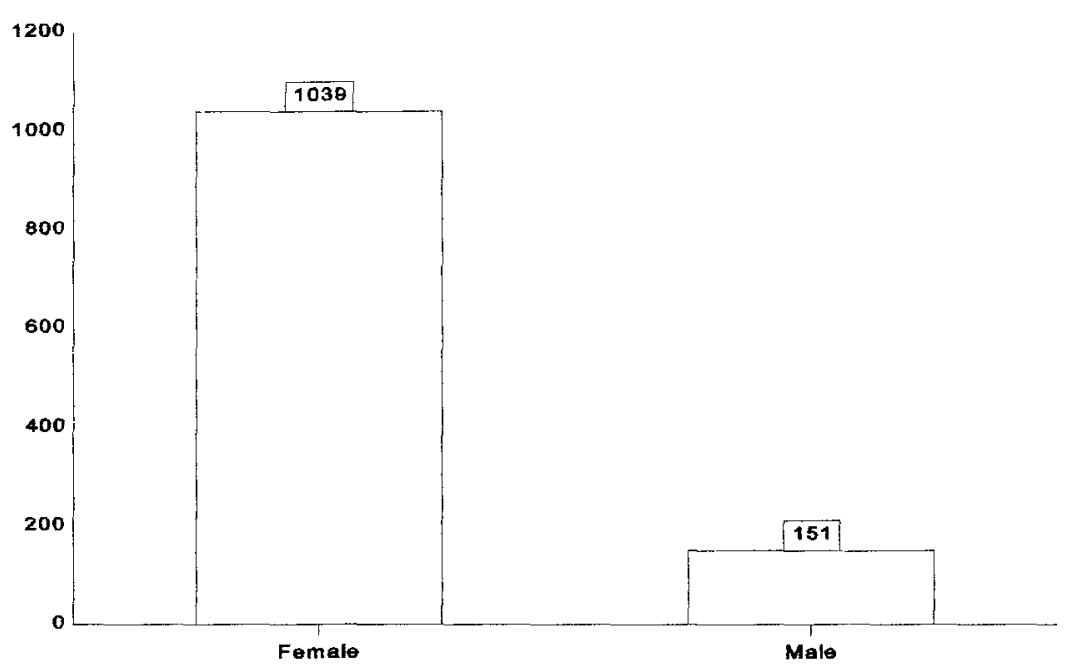

Missing cases: 6

Total number of respondents: 1,196

Figure 1. Instructors' gender.

\section{Education}

Highest Level of Education

A majority $(52 \%)$ of the instructors reported that they had attended a university, and about $35 \%$ said that they had attended graduate school. Instructors who did not pursue studies beyond high school or college were relatively few $(6 \%$ and $7 \%$ respectively). Twelve respondents did not indicate the highest level of education they had achieved.

\section{Degrees}

Table 2 shows the type of degrees held by instructors who pursued studies beyond high school, indicating the percentages of instructors holding each type of degree. Because an individual instructor may hold more than one degree, the total number of degrees $(2,080)$ exceeds the total number of instructors who responded to this questionnaire item $(1,184)$. Although data collected on the respondents' highest level of education indicated that $35 \%$ of instructors had attended graduate school, Table 2 shows that only $14 \%$ of those instructors had obtained graduate degrees.

\section{Formal ESL Training and Qualifications}

A large majority of $88 \%$ of the respondents indicated that they had received formal ESL training. Only 118 instructors or $10 \%$ indicated that they had not received such training (22 respondents did not provide this information). 
Table 1

Instructor's Age

\begin{tabular}{lcc}
\hline Age & Number of instructors & $\%$ \\
\hline $20 \mathrm{~s}$ & 116 & 10 \\
$30 \mathrm{~s}$ & 275 & 24 \\
$40 \mathrm{~s}$ & 464 & 40 \\
$50 \mathrm{~s}$ & 268 & 23 \\
$60 \mathrm{~s}$ & 41 & 3 \\
\hline Total & 1,164 & 100 \\
\hline
\end{tabular}

Missing cases: 32

Total number of respondents: 1,196

Table 3 shows the percentages of instructors holding various types of ESL qualifications. In this case also, the total number of formal ESL qualifications $(1,286)$ exceeded the total number of ESL instructors who had formal ESL training $(1,056)$ as it was possible for one instructor to hold more than one type of formal ESL qualifications. Findings indicated that a large majority $(65 \%)$ of instructors held TESL certificates or diplomas.

Types of Agencies that Delivered ESL Teacher Training

As Table 4 indicates, a total of 937 respondents specified the types of agencies where they had undertaken ESL training. Two main findings were that $40 \%$ of these instructors received ESL training in universities and that $19 \%$ of instructors had been trained outside Canada.

Years During which Instructors Undertook ESL Training

Data obtained from 861 respondents who specified during which years they received ESL training indicated that a majority of $65 \%$ of instructors were trained in the 1990s; another $27 \%$ were trained in the 1980 s; very few $(7 \%)$ were trained in the 1960s and 1970s.

\section{ESL Teaching Practicum}

Among the 855 respondents who indicated whether their ESL training included a teaching practicum $65 \%$ reported that they had engaged in a teaching practicum as part of their training.

When instructors assessed the value of their ESL teacher training programs for their teaching practice, they rated their training programs much more favorably when ESL teaching practica were included. As shown in Figure 2, 80\% of the respondents who undertook ESL training that included a practicum rated their ESL training as "very useful," whereas only $20 \%$ of those who did not engage in a teaching practicum rated their training as 
Table 2

Instructors' Degrees

\begin{tabular}{lcc}
\hline Degrees & Number of Degrees & $\%$ \\
\hline College diploma & 152 & 7 \\
Ontario Teacher's Certificate & 680 & 33 \\
Undergraduate degree & 948 & 46 \\
MEd & 93 & 4 \\
MA/MSc & 184 & 9 \\
PhD & 23 & 1 \\
\hline Total & 2,080 & 100 \\
\hline
\end{tabular}

Table 3

Instructors' Formal ESL Qualifications

\begin{tabular}{lcr}
\hline Type of ESL Qualifications & Number of ESL Qualifications & $\%$ \\
\hline TESL Diploma/Certificate & 835 & 65 \\
Additional Qualifications in ESL Part II & 167 & 13 \\
Additional Qualifications in ESL Part III & 61 & 5 \\
Adult Ed. Qualifications & 178 & 14 \\
Other & 45 & 3 \\
\hline Total & 1,286 & 100 \\
\hline
\end{tabular}

Table 4

Types of Agencies that Delivered ESL Training

\begin{tabular}{lcc}
\hline Types of agency & Number of instructors & $\%$ \\
\hline University & 372 & 40 \\
College & 61 & 6 \\
School board & 111 & 12 \\
Ministry & 37 & 4 \\
Private & 17 & 2 \\
Institutions outside Canada & 176 & 19 \\
Several institutions & 163 & 17 \\
\hline Total & 937 & 100 \\
\hline
\end{tabular}

Missing Cases: 259

Total number of respondents: 1,196 


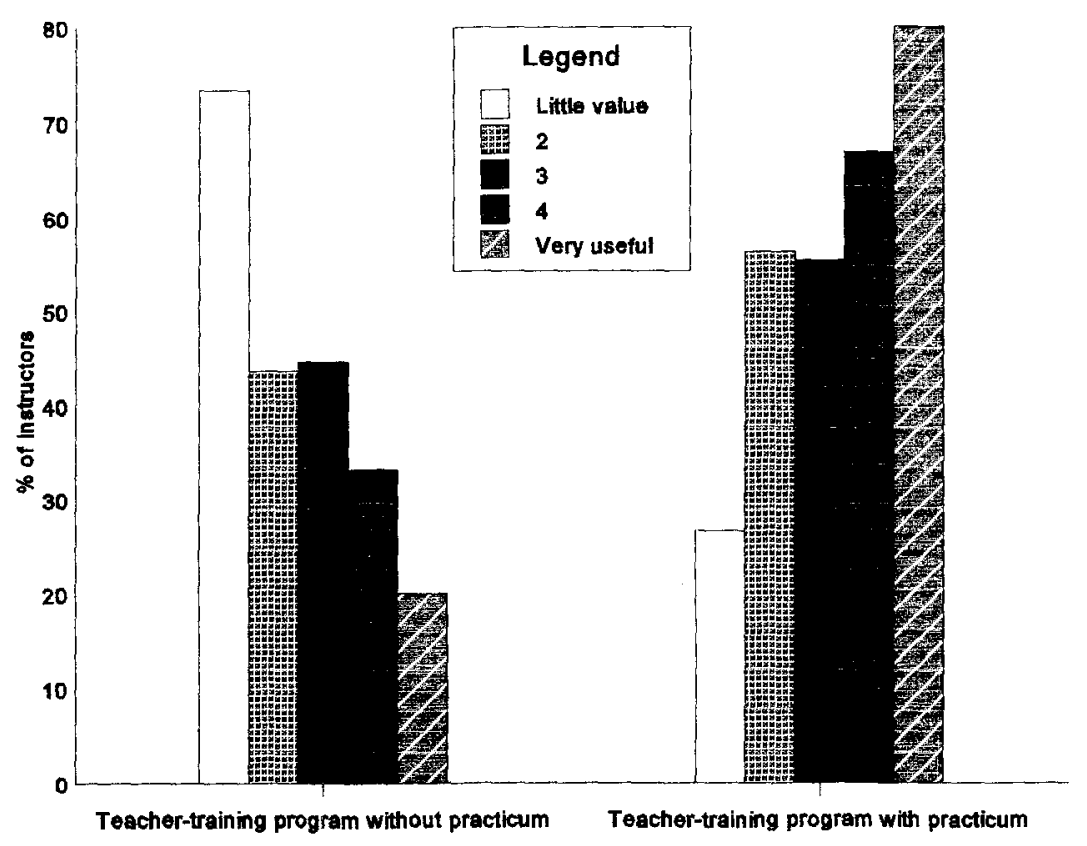

Missing cases: 381

Total number of respondents: 1,196

Figure 2. Teaching practicum by value of ESL teacher training program.

"very useful." Conversely, $73 \%$ of instructors who had not completed a practicum reported that their training program had been "of little value" to their teaching practice, whereas only $27 \%$ of instructors who had completed a practicum rated their training as such.

\section{ESL Teaching Experience}

Years of ESL Teaching Experience

Data on the respondents' years of experience teaching ESL indicated that $48 \%$ had between 1 and 5 years of ESL teaching experience and $28 \%$ had between 6 and 10 years. The proportion of instructors who had more than 10 years of ESL teaching experience was smaller, with $13 \%$ of instructors having taught between 11 and 15 years, 5\% having taught between 16 and 20 years, and $6 \%$ having 21 years of ESL teaching experience or more. Twenty-six respondents did not provide this information.

Type of ESL Teaching Experience

About $37 \%$ of the respondents (or 439 instructors) indicated that they had taught only in Ontario. Almost $62 \%$ (or 732 instructors) indicated that they 
had taught ESL elsewhere (25 cases were missing), 615 of whom indicated the types of agencies and geographical locations where they had taught: $45 \%$ (or 282 instructors) had taught in school boards; about 35\% (or 210 instructors) had taught in Canada. About 22\% (or 138 instructors) had experience teaching in Asia, 18\% (or 114 instructors) had taught in several countries, and $23 \%$ (or 140 instructors) had taught in several types of agencies.

\section{Experience Teaching Other Subjects}

A large majority of respondents (67\% or 797 instructors) had taught subjects other than ESL (33\% or 399 instructors had not). Furthermore, $47 \%$ of these instructors had between 1 and 5 years' experience teaching other subjects and $27 \%$ had between 6 and 10 years' experience. The proportion of instructors who had more than 10 years' experience was much smaller.

\section{Instructors' Employment}

Instructors' Employment by Agency Type

Figure 3 shows the types of agencies where instructors were employed in March 1995 and their distribution by agency type.

\section{Instructors' Highest Level of Education and Degrees by Agency Type}

Findings concerning the instructors' highest level of education by agency type were the following: the highest level of education for over half of the instructors employed by school boards, community-based and private agencies was university education; about $70 \%$ of instructors employed in universities and $47 \%$ of instructors employed in colleges had attended graduate school; about $6 \%$ of instructors working in school boards had only attended high school.

However, when proportions of (completed) degrees were examined by agency type (see Table 5), it was found that most instructors in all types of agencies held undergraduate university degrees and/or an Ontario Teacher's Certificate (OTC).

\section{Instructors' Teaching Experience by Agency Type}

The main findings concerning instructors' teaching experience by agency type (see Table 6) were the following: community-based agencies, private agencies, and school boards had the largest proportion of instructors with 1-5 years teaching experience. Universities and school boards had the largest proportion of instructors with 6-10 years teaching experience. Colleges and universities had the largest proportion of instructors with 11-21 years teaching experience.

The distribution of instructors who had formal ESL training and those who had no ESL training was also examined by agency type. Findings indicated that the $10 \%$ of instructors who reported they had no ESL training were distributed relatively evenly across all agency types. 


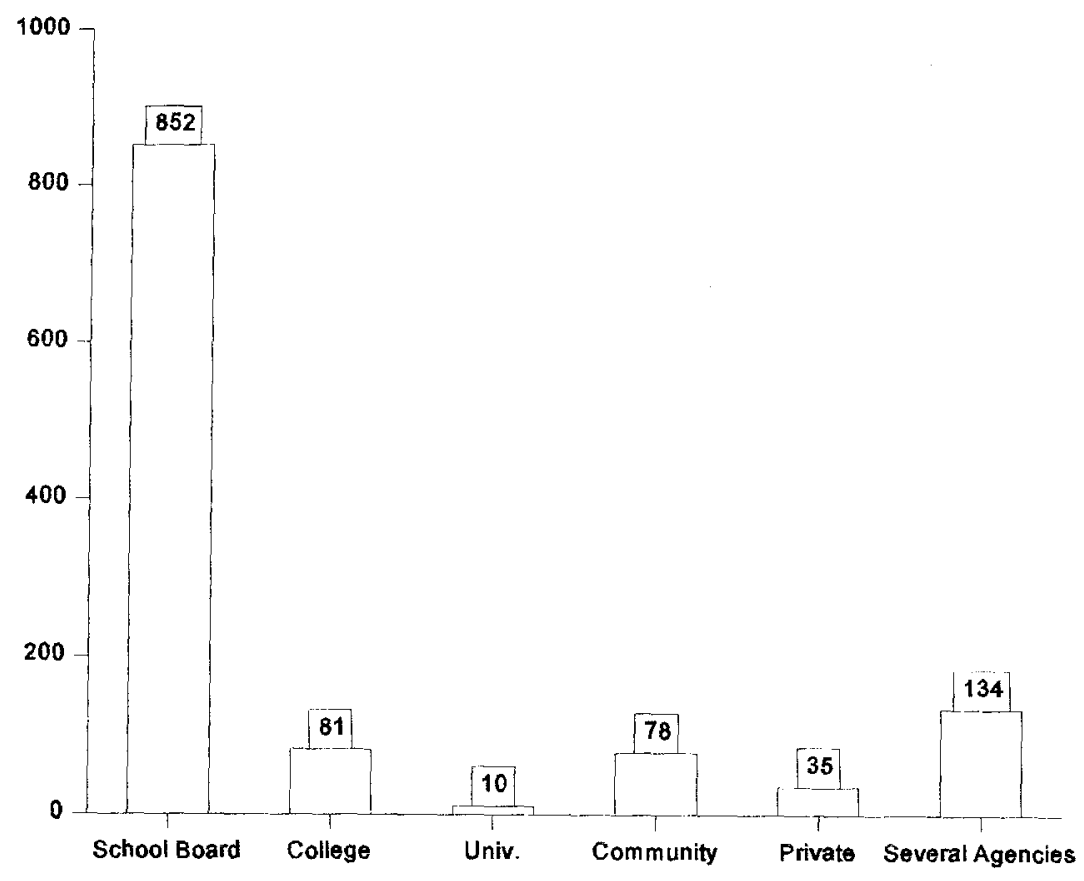

Missing cases: 6

Total number of respondents: 1,196

Figure 3. Instructors' employment by agency type in March 1995.

Table 5

Percentage of Instructors with Degrees by Agency Type

\begin{tabular}{llllllll}
\hline Agency Type & $\begin{array}{l}\text { College } \\
\text { Diploma }\end{array}$ & OTC & $\begin{array}{c}\text { Undergraduate } \\
\text { Degree }\end{array}$ & M.Ed & M.A.M.Sc & Ph.D. & Total \\
\hline School Board & $8(n=116)$ & $34(\mathrm{n}=492)$ & $45(\mathrm{n}=667)$ & $4(\mathrm{n}=59)$ & $8(\mathrm{n}=123)$ & $1(\mathrm{n}=15)$ & 1,472 \\
College & $3(\mathrm{n}=5)$ & $36(\mathrm{n}=59)$ & $44(\mathrm{n}=72)$ & $7(\mathrm{n}=11)$ & $10(\mathrm{n}=16)$ & $1(\mathrm{n}=2)$ & 165 \\
University & $9(\mathrm{n}=2)$ & $22(\mathrm{n}=5)$ & $39(\mathrm{n}=9)$ & $4(\mathrm{n}=1)$ & $22(\mathrm{n}=5)$ & $4(\mathrm{n}=1)$ & 23 \\
Community-based & $5(\mathrm{n}=7)$ & $30(\mathrm{n}=41)$ & $50(\mathrm{n}=69)$ & $4(\mathrm{n}=5)$ & $10(\mathrm{n}=14)$ & $1(\mathrm{n}=2)$ & 138 \\
Private & $5(\mathrm{n}=3)$ & $22(\mathrm{n}=12)$ & $54(\mathrm{n}=30)$ & $2(\mathrm{n}=1)$ & $13(\mathrm{n}=7)$ & $4(\mathrm{n}=2)$ & 55 \\
Several Agencies & $8(\mathrm{n}=18)$ & $31(\mathrm{n}=68)$ & $44(\mathrm{n}=97)$ & $7(\mathrm{n}=16)$ & $9(\mathrm{n}=19)$ & $0.5(\mathrm{n}=1)$ & 219 \\
\hline Total & $7(\mathrm{n}=151)$ & $33(\mathrm{n}=677)$ & $46(\mathrm{n}=944)$ & $4(\mathrm{n}=93)$ & $9(\mathrm{n}=184)$ & $1(\mathrm{n}=23)$ & $\mathrm{N}=2,072$ \\
\hline
\end{tabular}

Missing cases: 16

Total number of Respondents: 1,196 
Types of ESL Classes Taught by Instructors and Additional Duties

Respondents were asked to indicate the types of ESL classes they were currently teaching. Findings indicated that the three predominant types of ESL classes taught by the respondents were Language Instruction for Newcomers to Canada (LINC), ESL literacy, and regular ESL classes. Also, most of these classes were taught by instructors employed in school boards.

Instructors in all types of agencies reported engaging in a large range of duties in addition to teaching. Additional duties included student placement and assessment, program planning, curriculum and material development, training and hiring staff, policy decisions, written communications (i.e., publications in newsletters and journals), or presentations at conferences. ${ }^{2}$

\section{Conditions of Employment}

Hourly Rate of Pay

The hourly rate of pay reported by the respondents ranged from $\$ 6-83$ with a mean of $\$ 28.80$. Findings concerning the hourly rate of pay by agency type indicated that most instructors employed by school boards, communitybased or private agencies earned between $\$ 21$ and $\$ 30$ per hour, whereas most instructors employed by universities and colleges earned between $\$ 31$ and $\$ 50$ per hour (163 respondents did not provide this information).

Hourly Rate of Pay by Type of Degree

The hourly rate of pay was examined in relation to the type of degrees instructors held (see Table 7). Findings indicated that most instructors earned between $\$ 21$ and $\$ 30$ per hour; this trend tended to hold for most degree categories. A small proportion of the instructors (about $25 \%$ ) holding the same types of degrees earned between $\$ 31$ and $\$ 50$ per hour.

Table 6

Instructors' Years of ESL Teaching Experience by Agency Type

\begin{tabular}{lcccccc}
\hline Agency Type & $1-5$ years & 6 -10 years & $11-15$ years & $16-20$ years & $21+$ years & Totals \\
\hline School Board & 397 & 256 & 103 & 40 & 39 & 836 \\
College & 17 & 11 & 20 & 14 & 10 & 81 \\
University & 2 & 5 & 2 & - & 1 & 10 \\
Community-based & 54 & 15 & 5 & 1 & 2 & 77 \\
Private & 23 & 4 & 5 & 2 & 1 & 35 \\
Several & 65 & 35 & 18 & 7 & 4 & 129 \\
\hline Totals & 558 & 326 & 153 & 64 & 66 & 1,167 \\
\hline
\end{tabular}

Missing cases: 29

Total number of respondents: 1,196 


\section{Hourly Rate of Pay by Type of ESL Qualifications}

The hourly rate of pay was further examined in relation to the formal ESL qualifications instructors held (see Table 8). Findings indicated that most instructors who had completed a TESL certificate/diploma or Additional Qualifications (AQ) in ESL Part II or AQ Part III earned between $\$ 21$ and $\$ 30$ per hour; a small proportion of these instructors $(20 \%)$ earned between $\$ 31$ and $\$ 50$ per hour. The hourly rate of pay was also examined in relation to whether instructors had or had not had ESL training. Findings indicated that the $10 \%$ of instructors who had no ESL training received the same hourly rate of pay as those who had ESL training.

Hours of ESL Classroom Instruction per Week by Agency Type

The number of hours of ESL classroom instruction per week reported by the respondents ranged from 1-43 with a mean of 18.22 (49 cases were missing). Findings concerning the hours of instruction per week by agency type indicated that most instructors employed by school boards, community-based and private agencies taught ESL more than 20 hours a week; most of those employed by colleges taught between 16 and 20 hours a week; most of those employed by universities taught fewer than 10 hours a week ( 57 cases were missing). Findings about the number of weeks of work instructors performed per year by agency type are not reported because 474 respondents did not provide this information.

\section{Short-Term and Permanent Contracts}

Only 963 instructors indicated whether they were permanent employees or employed on the basis of short-term contracts. About $76 \%$ of these respondents indicated that they were employed on the basis of short-term contracts, whereas $24 \%$ reported that they were permanent staff. Findings indicated that all agency types employed more instructors on short-term contracts than

\section{Table 7}

Instructors' Hourly Rate of Pay by Type of Degree

\begin{tabular}{lrrrrrr}
\hline Type of degrees & $\$ 6-10$ & $\$ 11-20$ & $\$ 21-30$ & $\$ 31-50$ & $\$ 51+$ & Totals \\
\hline OTC & 3 & 28 & 398 & 147 & 10 & 586 \\
College Diploma & - & 13 & 94 & 22 & 2 & 131 \\
University Degree & 4 & 62 & 573 & 181 & 11 & 831 \\
MEd & - & 3 & 57 & 12 & 2 & 74 \\
MA/MSc & 1 & 7 & 102 & 40 & 6 & 156 \\
PhD & - & 2 & 13 & 6 & - & 21 \\
\hline Totals & 8 & 115 & 1,237 & 408 & 31 & 1,799 \\
\hline
\end{tabular}


Table 8

Hourly Rate of Pay by Type of Formal ESL Qualifications

\begin{tabular}{lrrrrrr}
\hline $\begin{array}{l}\text { Types of ESL } \\
\text { qualifications }\end{array}$ & $\$ 6-10$ & $\$ 11-20$ & $\$ 21-30$ & $\$ 31-50$ & $\$ 51+$ & Totals \\
\hline TESL Certificate & 1 & 46 & 506 & 173 & 6 & 732 \\
AQ Part II & 1 & 10 & 100 & 30 & 1 & 142 \\
AQ Part III & - & 1 & 35 & 12 & 1 & 49 \\
Adult Ed. training & 1 & 9 & 107 & 34 & 1 & 152 \\
Other & - & 2 & 24 & 15 & 1 & 42 \\
\hline Totals & 3 & 68 & 772 & 264 & 10 & 1,117 \\
\hline
\end{tabular}

permanent staff, except for colleges that employed a slightly larger number of permanent instructors.

\section{Duration of Contracts}

Only 626 of the 732 instructors working on short-term contracts specified the duration of their contracts. The duration of short-term contracts ranged from 1-24 months with a mean of 8.58 months. Instructors working in school boards, community-based and private agencies were generally offered contracts of 12 months duration, whereas those employed in colleges and universities were generally offered six-month contracts.

\section{Collective Agreements}

A total of 470 instructors (or 39\%) indicated that they had collective agreements; 199 had agreements with the Canadian Union of Public Employees (CUPE), 136 with the Teachers' Federation, 63 with the Ontario Public Service Employee Union (OPSEU), and 29 had other types of collective agreements. Findings also indicated that 318 instructors, that is, $75 \%$ of those instructors who had collective agreements, were school board employees.

\section{Benefits}

Information provided by the respondents about benefit packages indicated that $30 \%$ of instructors had benefit packages, $58 \%$ had no benefit package, and $9 \%$ reported that their employers offered optional benefits that they could purchase. Findings also showed that the proportions of instructors who had no benefit package were larger than the proportions of instructors who had benefit packages in all agency types, except in colleges (29 cases were missing).

\section{Instructors' Perceptions of Job Security}

Respondents were asked to rate their job security on a 5-point scale where $1=$ insecure, and $5=$ very secure. About $40 \%$ of the respondents (or 421 instruc- 
tors) assigned a rating of 1 , indicating that they were insecure about their jobs. Only $4 \%$ or 52 instructors indicated that they were very secure about their jobs (66 instructors did not provide this information). Analyses of the respondents' ratings of job security by agency type suggested that most instructors in all agency types felt insecure about their jobs. Further analyses also indicated that instructors who did not have collective agreements felt more insecure about their jobs than those who had collective agreements; more part-time than full-time instructors felt insecure about their jobs; and more instructors working on the basis of short-term contracts felt insecure about their jobs.

\section{Professional Development}

Ninety-eight percent of respondents reported that professional development opportunities were offered to them by their employers. Furthermore, all agency types offered instructors a variety of professional development activities, including workshops, conferences and courses. Most instructors in school boards reported that financial support was not provided, whereas most instructors in colleges and community-based agencies indicated that financial support was provided.

A large majority of instructors (73\%) indicated that they participated in professional development activities independently of their employers. This finding held across agency types.

Workshops and conferences were the two types of professional development activities in which instructors participated most, independently of their employers. About $90 \%$ of the instructors rated workshops, conferences, courses and other inservice activities from "useful" (a rating of 3) to "very useful" (a rating of 5), suggesting that most instructors valued most types of professional development activities.

\section{Professional Issues of Concern to Instructors}

The participants were asked to identify professional issues of concern to them and provide recommendations to address these issues. Although individual instructors expressed a broad range of concerns, there was remarkably strong consensus among the respondents as to issues they perceived as most pressing and the recommendations they offered. The main issues of concern related to: (a) instructors' conditions of employment; (b) teacher certification; (c) instructors' access to professional development; (d) government policies for adult ESL education; and (e) program delivery and instruction. The most prevalent issues of concern in these five categories are summarized below. 
Conditions of employment

- Standards of employment (e.g., benefits and length of contracts) in agencies that employ ESL instructors to teach in non-credit programs for adults vary. Also, instructors reported significant discrepancies in the conditions of employment offered to them and those offered to instructors working in ESL credit programs in the same institutions or similar agencies.

- Instructors' job insecurity is largely due to the instability of funding allocated to agencies for ESL services; instructors' employment on short-term basis hinders their opportunities to develop viable ESL programs.

Teacher certification

- There are no uniform standards in Ontario for the certification of non-credit adult ESL instructors. As a result, employers' decisions for the hiring and advancement of these instructors vary considerably; employers' decisions are based on ad hoc assessments of ESL credentials and teaching experience.

Professional development

- Instructors who do not hold an Ontario Teacher's Certificate are not eligible to enroll in the Ministry of Education and Training's Additional Qualification Courses in ESL. Many ESL instructors who already hold an undergraduate university degree would be required to complete a second university degree in order to obtain an Ontario Teacher's Certificate. Programs of study leading to an Ontario Teacher's Certificate do not emphasize issues of ESL education because ESL is not a teaching subject in Ontario's faculties of education.

- Instructors reported they were offered few opportunities for professional development focusing on adult ESL learners with physical disabilities, antiracist education, ESL literacy, or cultural awareness.

Government policies

- There is a need for a provincial policy regulating ESL education for adults; there is also a need for a central student registry to monitor transfers of students between non-credit ESL programs and to record total services provided to individuals.

- There is a need for better coordination between federal and provincial levels of government as to provision of ESL services.

Program delivery and instruction

- Non-credit ESL programs for Adults vary significantly in their policies and procedures for ESL proficiency assessment and student placement; there are also significant variations in curricula used in similar programs. 
- Classroom facilities in which ESL instruction is delivered raise health and safety concerns for instructors and students, especially in non-credit programs operating in church basements and community centers.

- ESL curricular and pedagogical materials with Canadian content appropriate for adult learners are scarce.

\section{Instructors' Recommendations}

The respondents stressed that all issues they identified impacted directly or indirectly on the quality of ESL instruction and other services offered to adult ESL learners, their success in learning English, and abilities to participate in society. A synthesis of the respondents' suggestions for addressing these issues resulted in six main recommendations:

- Establish uniform standards for employing instructors to teach ESL to adults in non-credit programs in Ontario.

- Establish a protocol and uniform standards for the certification of non-credit Adult ESL instructors in Ontario.

- Establish a provincial policy for adult ESL education, ensuring better coordination of ESL services under the jurisdictions of provincial and federal levels of government.

- Establish ESL as a teaching subject in faculties of education of Ontario's universities to emphasize the need for ESL education and promote recognition of the ESL teaching profession.

- Establish standard curricula and mechanisms for assessing ESL proficiency in similar non-credit programs for adults and create a central bank of curricular materials and assessment tools to support curriculum implementation.

- Ensure that instructional facilities for ESL delivery in non-credit programs conform to Ontario's health and safety regulations pertaining to educational settings.

\section{Limitations of the Study}

An important limitation of the study is that it did not determine which proportion of the total number of non-credit Adult ESL instructors currently teaching in Ontario participated in this survey. Efforts were made to survey all agencies in Ontario that employed non-credit Adult ESL instructors. However, there was no preexisting list of these instructors that could have defined this population precisely. Because the total number of ESL instructors working in any one agency could not be determined prior to distributing the questionnaire, program administrators working in these agencies received multiple copies of the survey instrument with instructions to make additional copies according to the number of instructors employed in their non-credit ESL programs. A preliminary count of the total population of 
non-credit Adult ESL instructors currently teaching in Ontario or records of the number of questionnaires that each surveyed agency had reproduced would have been helpful in assessing the return rate of the questionnaire and the representativeness of the sample of respondents.

Despite this important limitation, the large number of respondents and the detailed information obtained from them allowed for a comprehensive description of the participants' professional characteristics, situations, concerns, and recommendations. Such a detailed profile of 1,196 instructors of non-credit Adult ESL could not easily have been compiled from other sources to inform officials of the Ontario Ministry of Education and Training, Citizenship and Immigration Canada, the Ontario Ministry of Citizenship, Culture and Recreation, and TESL Ontario in their decisions concerning the development of a protocol and uniform standards for the certification of non-credit Adult ESL instructors in Ontario.

In the next stage of the project a focus group organized to represent various stakeholders across Ontario will make recommendations to a steering committee about the certification of non-credit adult ESL instructors. In order to do so, members of the focus group will interpret and decide how to use these research findings in light of findings from a survey of teacher preparation programs in Ontario and a careful examination of academic, professional, legal, financial, social, and political issues associated with the establishment of uniform teacher certification standards.

Although it focuses on Ontario, this research is also relevant to the ESL profession in other parts of Canada. First, the research draws attention to instructors teaching in non-credit adult ESL programs that exist across the country. This focus is timely given recent developments affecting a federally funded program that currently employs a large proportion of non-credit adult ESL instructors in Canada, namely the Language Instruction for Newcomers to Canada (LINC) program. The federal government has announced plans to devolve funding for this program by 1998 (Citizenship and Immigration Canada, 1996). Whether and how individual provinces will take some responsibilities for the LINC program is uncertain. At present, British Columbia, Manitoba, and Alberta have agreed to integrate provincial and federal levels of funding for the program. Ontario is currently negotiating an agreement with the federal government on this issue. These developments have potential effects on many aspects of that program, including the situation of the instructors it currently employs.

Second, the study highlights a broad range of important concerns for non-credit adult ESL, corroborating issues previously discussed in the literature. For example, in her discussion of teacher development and recognition in language training programs for adult immigrants in Canada (most of which are non-credit), Burnaby (1992) pointed out that "the combination of difficult teaching situations with low status and insecurity in employment is 
a source of a great deal of frustration in the ESL profession" (p. 25). Cumming's (1991) empirical study of current needs and issues related to the delivery of adult ESL instruction in British Columbia also emphasized needs to "provide more ESL teacher training, better employment conditions for teachers, instructional materials and resources, and policies for coordination and evaluation of programs" (p. 145). Such concerns were also voiced by many adult ESL professionals from various parts of the country in the context of a symposium on teacher certification held at the 1994 TESL Canada Conference, ${ }^{3}$ suggesting that the situation of Ontario's non-credit adult ESL instructors described in this study might be generally similar to the situation of their counterparts in different parts of the country.

Furthermore, this project draws attention to issues of ESL teacher certification, contributing a description of the systematic process that a provincial ESL organization is following to delineate uniform standards. Interest in this important issue has recently increased in Canada, judging from the ongoing efforts of individual provinces (Harrold 1995) and the recent creation of a TESL Canada Certification Special Interest Group intending to explore possibilities for uniform ESL teacher certification standards at the national level (Bégin 1996).

\begin{abstract}
Notes
${ }^{1}$ Most instructors provided extensive responses. Quantitative analyses of these data were beyond the resources for this study. No quantitative measure was applied to the grouping of the instructors' responses.

${ }^{2}$ Preparation for teaching and marking of assignments are assumed under Teaching. Information about the proportion of marking and preparation to contact hours of instruction was not collected. Additional duties do not carry additional pay.

${ }^{3}$ The symposium on "Certification of Instructors Teaching Non-Credit ESL to Adults: Issues and Options" held at the TESL Canada Conference in November 1994 in Toronto included the following presenters: Tracey Derwing, University of Alberta; Jennifer House, Vancouver Community College; Razika Sanaoui, York University; Kelleen Toohey, Simon Fraser University; and David Wood, Mount Royal College, Calgary.
\end{abstract}

\title{
Acknowledgements
}

This project was funded by the Ontario Ministry of Education and Training. I thank Linda Perry from the Career and Adult Education Unit of this Ministry for coordinating all aspects of data collection for this project. I also thank Ling Shi from the Ontario Institute for Studies in Education who assisted with data entry into computer files and data analyses. Elizabeth Taborek and Linda Curtis of the TESL Ontario Executive Committee provided valuable support and encouragement. This article is based on a report submitted to the Ontario Ministry of Education and Training (Sanaoui, 1996b); a progress report was published in TESL Ontario's newsletter (Sanaoui 1996a). 


\section{The Author}

Razika Sanaoui ( $\mathrm{PhD}, \mathrm{OISE} /$ University of Toronto) is an assistant professor in the Faculty of Education of York University where she teaches graduate and undergraduate course in English and French as a Second Language education. She has published articles on second language writing, vocabulary learning and instruction, and computer communications for second language development and teacher education. As the Research Chair of TESL Ontario, she is conducting research leading to the development of a certification protocol for ESL instructors.

\section{References}

Bégin, S. (1996, December). TESL certification. TESL Canada Bulletin, p. 7.

Burnaby, B. (1992). Official language training for adult immigrants in Canada: Features and issues. In B. Burnaby \& A. Cumming (Eds.), Socio-political aspects of ESL in Canada (pp. 3-34). Toronto: OISE Press.

Citizenship and Immigration Canada. (1996). Round 2 consultation on settlement renewal: Finding a new direction for newcomer integration. Ottawa, ON: Author.

Cumming, A. (1991). Identification of current needs and issues related to the delivery of adult ESL instruction in British Columbia. Victoria, BC: Ministry of Provincial Secretary and Ministry Responsible for Multiculturalism and Immigration. (ERIC ED 353 855)

Harrold, D.K. (1995). Accreditation/certification for adult ESL instructors in Canada: An overview. TESL Canada Journal, 13(1), 37-62.

Sanaoui, R. (1996a). Characteristics of instructors teaching non-credit adult ESL in. Ontario: A progress report of TESL Ontario's research study. Contact, 21(2), 29-30.

Sanaoui, R. (1996b). Professional characteristics and concerns of instructors teaching English as a second language to adults in non-credit programs in Ontario. Report submitted to the Ontario Ministry of Education and Training.

Sanaoui, R. (1997). Directory of ESL teacher preparation programs in Ontario. Toronto, ON: TESL Ontario. 


\section{TESL ONTARIO ADULT ESL INSTRUCTOR SURVEY}

\section{DEMOGRAPHIC INFORMATION}

Age:

Gender $\quad \mathrm{M}_{-} \mathrm{F}_{\text {_ }}$

Highest grade/diploma/degree obtained:

Years of experience teaching ESL :

Full-time

Part-time

Have you taught elsewhere previously? Yes

No

If yes, in which type of setting: (school board, college, etc.)

Where did you teach? (other provinces, countries)

Years of experience teaching other subjects:

2. WORK INFORMATION

Level(s) of ESL instruction you currently teach (please check those which apply):

Slass Types Average number of students per class

* ESL Literacy

* LINC

* LMLT

* Academic Preparation

* Workplace-based

* NLOC

* Other (e.g. pronunciation)

Please specify class type

\section{Your Employer is}

* School Board:

* College of Applied Arts and Technology:

* University:

* Community-based Agency:

* Private Trainer: 
* Other: (please specify)

Are you a Volunteer Instructor? Yes

No

If not, please calculate your hourly rate of pay (base rate without benefits):

How many classroom hours of instruction do you provide per week?

How many weeks per year do you teach ESL?

What are the conditions of your employment? Permanent Staff Contract

If contract, what is the duration?

Please indicate any other language(s) in which you are fluent and could teach ESL using a bilingual methodology ${ }^{1}$ ?

Are you currently teaching a bilingual program? Yes

No

In addition to your regular duties, do you participate in other committees, projects, or work groups: Yes No If so, please circle.

* Student Placement/Assessment

* Curriculum Development

* $\quad$ Staff Training

* Program planning

* Materials Development

* Staffing Decisions

* Communication (e.g. journal publications, newsletters)

* Research

* Other: (please specify)

Do you have a collective agreement? Yes No

If so, please circle.

Teachers Federation

CUPE

OPSEU

Other (Please specify):

Rate your sense of job security: Insecure $\begin{array}{llllll}1 & 2 & 3 & 4 & 5 & \text { Very secure }\end{array}$

Do you have a benefit package? Yes _ No ___ Optional buy-in If so, please circle:

* Sick Days

${ }^{1}$ Where the instructor shares the language and often the culture of the learners and uses the common first language as a support for language learning. For example, the teacher uses both Chinese and English in an ESL class for Chinese students. 
* Medical

* Dental

* Life Insurance

* Paid Vacation (beyond $4 \%$ mandatory)

* $\quad$ Other (please specify)

3. EDUCATION/TRAINING INFORMATION

Please indicate your formal qualifications:

Ontario Teaching Certificate or equivalent professional teacher training Undergraduate Degree (Bachelor of Arts, Bachelor of Education, etc.) College Diploma

M. Ed.

M.A. M.Sc.

Ph.D.

Other qualifications (Please specify)

Do you have formal ESL training? Yes No If yes, please indicate:

TESL Diploma/Certificate

Ministry A. Q. part II

Ministry A. Q. part III

Adult Education training

Other (Please specify)

If applicable, at what institution(s) have you obtained ESL training?

Length of Program:

Did it include a practicum? Yes No

How many hours

Number of courses (if applicable)

During which year(s) did you undertake training?

Please rate the practical value of your pre-service training for your teaching practice: Little value $1 \begin{array}{llllll}1 & 2 & 3 & 4 & 5 & \text { Very useful }\end{array}$

4. PROFESSIONAL DEVELOPMENT

What professional development opportunities are provided by your employer? Please circle: 


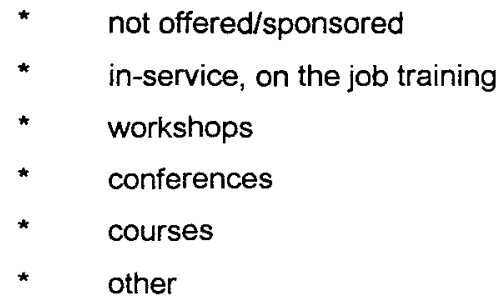

Have you participated in professional development related to ESL independent from your employer? Yes No How often?

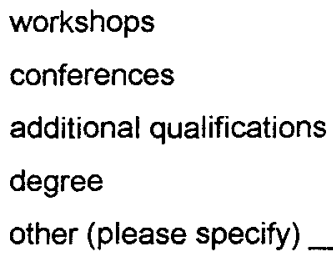

Please rate the usefulness of these forms of Professional Development for your teaching practice:

$$
\begin{aligned}
& \text { - in-service } \\
& \text { - workshops } \\
& \text { - conferences } \\
& \text { - courses }
\end{aligned}
$$

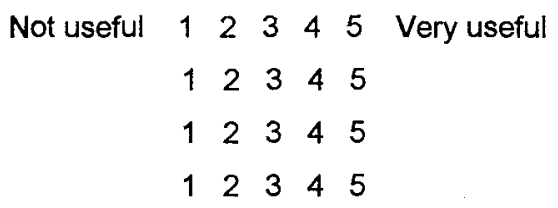

5. PLEASE ASSIST US TO IDENTIFY OUTSTANDING ISSUES OF CONCERN TO YOU IN ADULT ESL. (Please use the back of the page or attach a separate sheet if you require additional space for your response.)

6. PLEASE PROVIDE YOUR RECOMMENDATIONS TO ADDRESS THESE ISSUES. (Please use the back of the page or attach a separate sheet if you require additional space for your response.) 